\title{
PEDIATRIC TIBIAL SPINE FRACTURES - TREATMENT OPTIONS
}

\author{
Narcis Flavius Tepeneu ${ }^{1}$
}

\begin{abstract}
Pediatric fractures of the tibial spine are relatively rare and controversy remains around how these injuries are best managed. Consequently most non-specialized paediatric units have limited experience of managing these injuries. Injuries that rupture the ACL of an adult typically avulse the anterior tibial spine in a growing child. The conservative treatment of un-displaced fractures (type I) is unambiguous and simple. However, difficulties may arise in relation to the treatment of type II and III fractures, since an anatomical reduction of the fracture and reconstruction of the articular surface are required to preserve the function and the stability of the knee joint. Several methods have been described for the treatment of avulsion of tibial eminence, including operations performed by using either arthrotomy or arthroscopy. The fixation of the fragments can be performed by utilizing Kirschner wires, cerclage wires, intraosseal sutures, epiphyseal cannulated screws, screws led through the fragment and screws and bone anchors inserted retrogradely.
\end{abstract}

Keywords: Fracture, tibial spine, Meyers and McKeever classification, children

\section{Introduction}

Fractures of the tibial spine exhibit a bimodal age distribution, occurring in both the pediatric and adolescent populations. They commonly occur between the ages of 8 to 14 . Fracture of the tibial spine is relatively rare. The incidence is 3 per 100,000 pediatric trauma cases per year, accounting for only $5 \%$ of pediatric knee effusions [1]. Consequently most non-specialized pediatric units have limited experience of managing the injury.

The most common causes of these fractures are bicycle accidents and athletic activities.

The mechanism of injury is a combination of hyperextension and internal rotation at the knee, causing the anterior cruciate ligament (ACL) to become taut. This motion represents the same mechanism often attributed to ACL rupture. The difference between the two injuries is a reflection of the properties of pediatric bone, which is more vulnerable to injury than the ligament as opposed to the skeletally mature adult where the opposite is true.

Pediatric tibial spine fractures typically occur in isolation, but the equivalent adult injury commonly occurs in association with injury to other structures notably the menisci and collateral ligaments. Although the ACL rarely ruptures in children is commonly stretched during the injury leaving a degree of laxity, which may lead to subtle knee instability.

A child presenting with an acute swollen knee after falling from a bicycle should be presumed to have a fracture of the tibial spine until proven otherwise. Some children are unaware that anything is seriously wrong until the following day, when the painful hemarthrosis persists.

They are usually unable to bear weight on their affected extremity. On physical examination, there is often a large hemarthrosis because of the intra-articular fracture and limited motion due to pain, swelling, and occasionally mechanical impingement of the fragment in the intercondylar notch. Sagittal plane laxity is often present, but the contralateral knee should be assessed for physiologic laxity. Gentle stress testing should be performed to detect any tear of the medial collateral ligament (MCL) or lateral collateral ligament (LCL) or physeal fracture of the distal femur or proximal tibia.

The radiologic findings can be subtle, and the damage is always greater than the $\mathrm{x}$-ray shows. Wide radiolucent wings of articular cartilage from the weight-bearing surface of the tibia are attached to the small osseous fragment. Much more than the spine is lifted up and the fragment is usually partially detached. When the fragment is completely detached, meniscus are interposed or the fragment is rotated, and open reduction is required.

\section{Material and method}

A retrospective study in the period 01.06.201701.06.2020 was conducted on cases that were managed by the author of the article. A total of 5 cases were identified. A review of literature was also conducted.

\section{Results}

There were 3 male and 2 female patients, mean age of 10,2 years. 2 patients suffered a bicycle fall, 2 patients had skiing accidents, and one patient suffered a fall after a slip on wet grass during a football match. 3 patients had Type I one fractures and were successfully managed by conservative treatment in a cast. 1 patient had a Type II fracture and closed reduction and casting of the knee in hyperextension was successful at reducing the fracture. The patient was also managed by conservative treatment in a cast, the follow-up radiographs did not show any secondary displacement.

\footnotetext{
1"Victor Babes" University of Medicine and Pharmacy Timisoara, Romania
} 
The last patient had a Type III fracture and was managed by knee arthrotomy via an open medial parapatellar approach, open reduction and osteosynthesis with 2 cannulated epiphyseal screws and washers.
All cases had a favorable outcome with a full recovery of knee range of motion (ROM), good Tegner Lysholm score and good stability of the knee joint.

Table 1. Summary of patients

\begin{tabular}{|l|l|l|l|l|l|l|}
\hline Patient & Gender & $\begin{array}{l}\text { Age } \\
\text { (years) }\end{array}$ & $\begin{array}{l}\text { Myers and } \\
\text { McKeever } \\
\text { grade }\end{array}$ & Treatment & $\begin{array}{l}\text { Tegner } \\
\text { Lysholm } \\
\text { score }\end{array}$ & Complications \\
\hline 1 & M & 11 & I & Cast & 100 & None \\
\hline 2 & F & 10 & I & Cast & 98 & None \\
\hline 4 & M & 9 & I & Cast & 100 & None \\
\hline 5 & F & 12 & II & $\begin{array}{l}\text { Closed } \\
\text { reduction } \\
\text { +cast }\end{array}$ & 96 & None \\
\hline M & 9 & III & $\begin{array}{l}\text { Open } \\
\text { reduction }+2 \\
\text { cannulated } \\
\text { screws }+2 \\
\text { washers }\end{array}$ & 96 & None \\
\hline
\end{tabular}

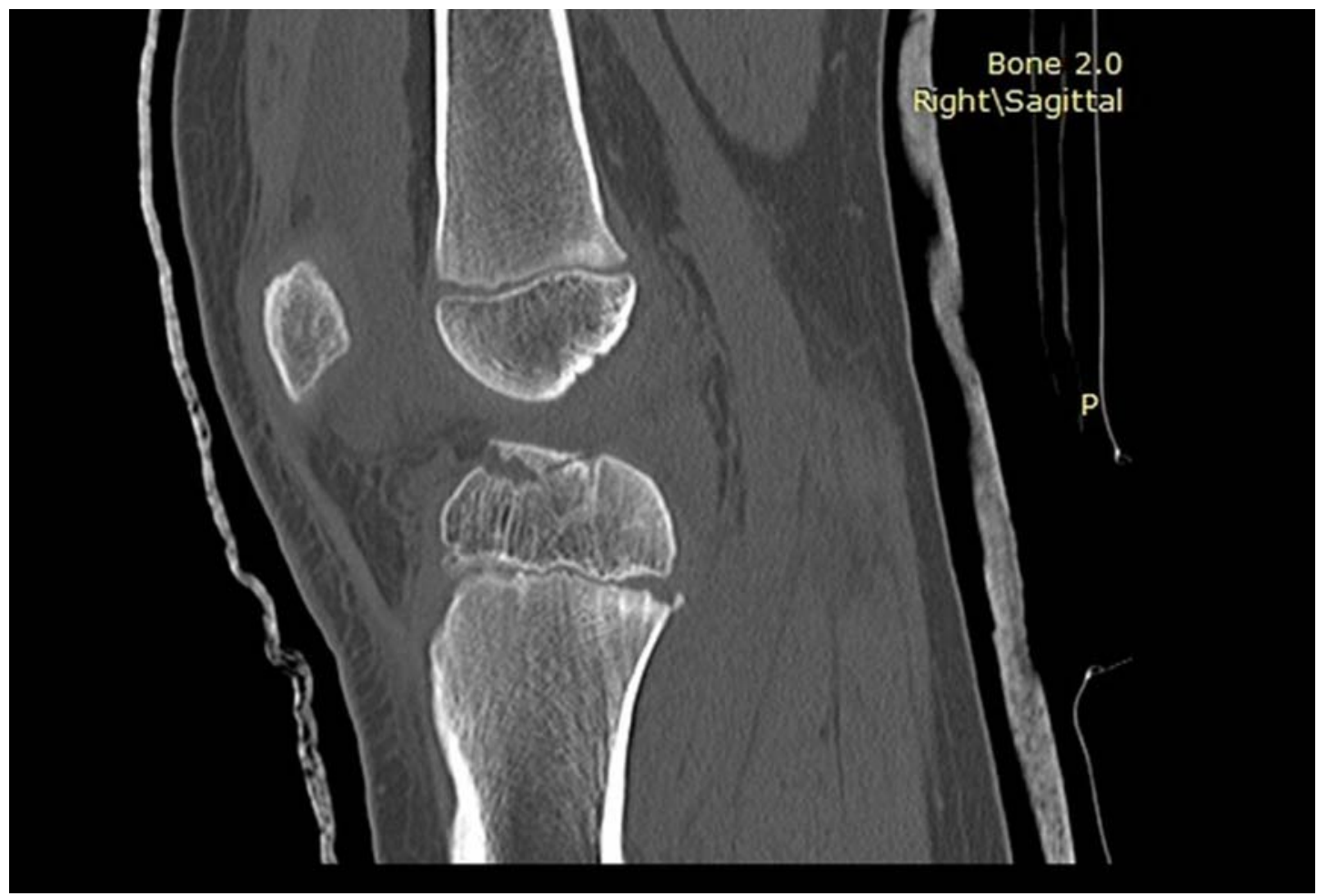

Fig. 1. Preoperative sagittal CT image of the right knee showing a Meyers and McKeever type III displaced tibial spine fracture 

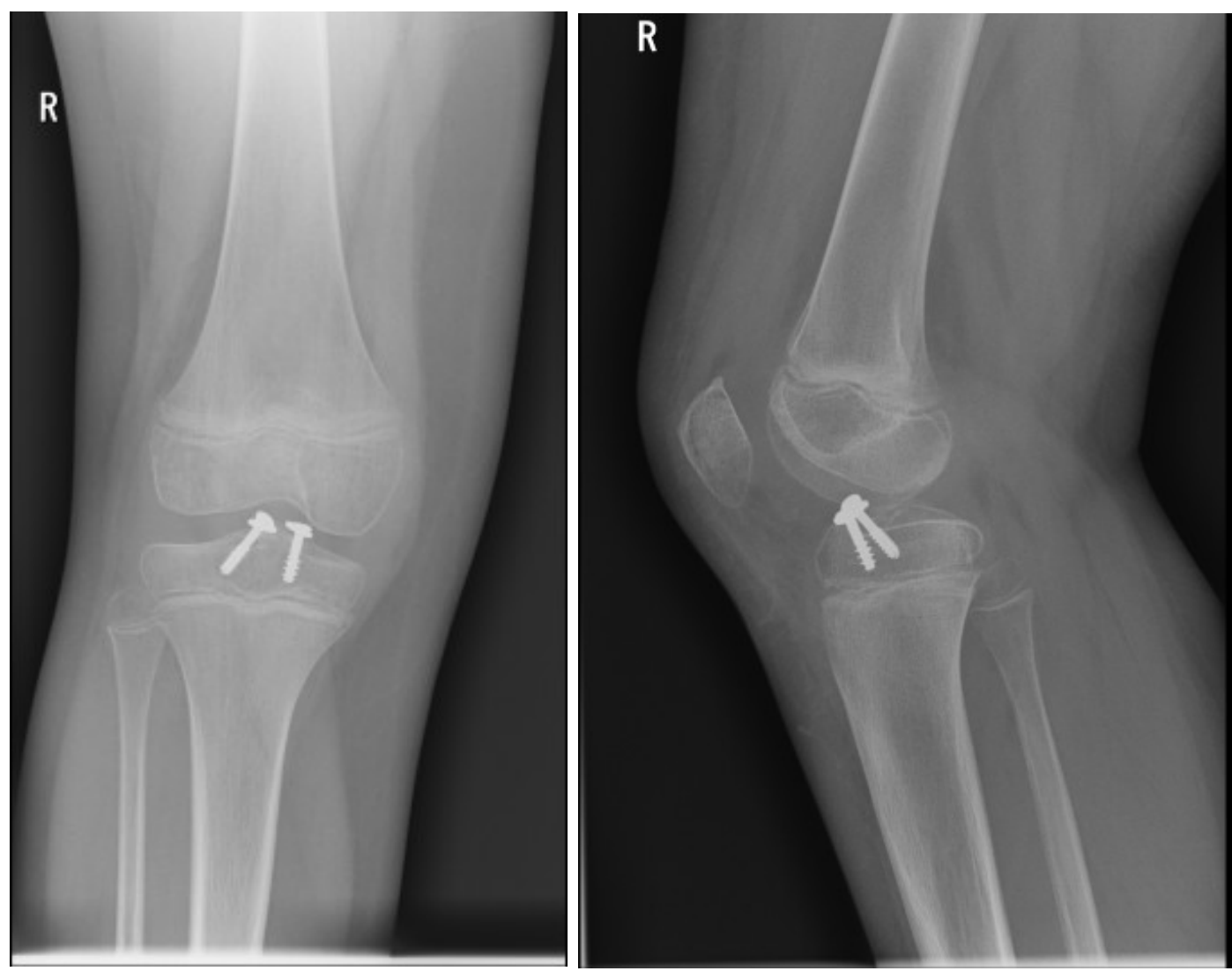

Fig. 2. Postoperative X-Ray images (4 month after surgery) showing a healed fracture with 2 cannulated epiphyseal screws and washers)
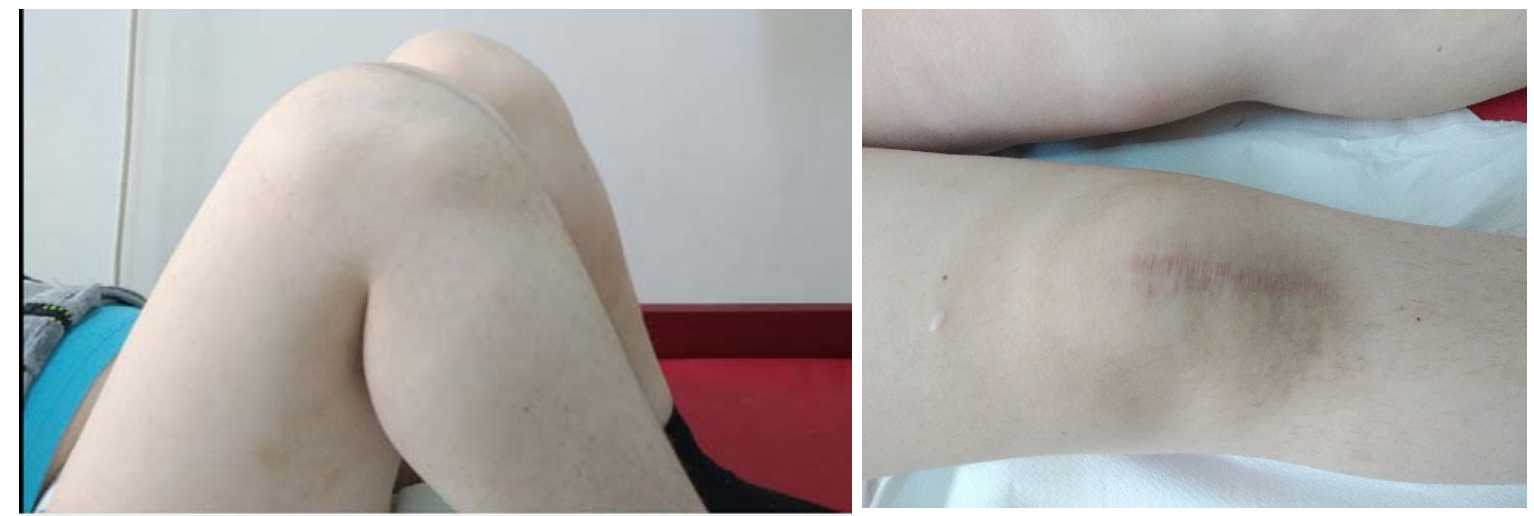

Fig. 3. Postoperative clinical images, showing symmetrical ROM of both knees

\section{Discussions}

The most serious limitation of our study is the small number of cases, due to the rarity of the pathology and the limited time interval. In most of our cases tibial spine fractures were sustained as a result of sporting injuries. This has been consistently reported in the literature and has been associated with activities ranging from cycling to skiing, which are representative of pivoting movements that would render the ACL taut $[2,3]$. Our results on the small number of cases indicate that both male and females are of equal risk of such an injury. To our knowledge, the available literature does not comment on the distribution of such fractures between the different genders. Conservative management, consisting of knee immobilization, is generally accepted as the treatment for Type I injuries $[4,5,6]$, although controversy remains regarding the preferred position of immobilization, from slight flexion to relax the ACL or full extension to allow the femoral 
condyles to reduce the tibial spine fragment. There are a wide range of management practices for type II and type III injuries reported in the literature [5]. Over the last 10-15 years there has been a gradual shift towards open reduction and internal fixation (ORIF) and more recently arthroscopic reduction and internal fixation (ARIF). [4,7] Within the ORIF and ARIF groups many techniques have been described including the use of screws, K-wires, suture anchors and more recently meniscal arrows. [7, 8, 9] Two systematic reviews evaluating the effectiveness of different methods of fixation did not show any conclusive evidence that any method was superior to the others $[4,7]$. Wilfinger et al. performed a retrospective clinical analysis on 38 pediatric reducible tibial spine fractures, which had all been treated in cast immobilization, regardless of the type of injury [3]. The authors reported that the overall functional outcome was good, with pain being reported as 'seldom' and mostly in patients that had type II and type III injuries. Although no objective knee scoring system was used and patient outcomes were recorded qualitatively, the outcomes in their type I and type II injuries were comparable to the patient outcomes in this study. This would suggest that rather than treating all type II injuries with surgery it would be of benefit to differentiate those type II injuries that are reducible, from those that are not, in order to establish which patients benefit from surgery. Edmonds et al. performed a retrospective study that documented the outcomes of paediatric patients that had either closed reduction or surgical fixation of their tibial spine fractures [5] The authors concluded that those type II injuries that had less than $5 \mathrm{~mm}$ elevation demonstrable on plain radiographs can be considered as minimally displaced and had good functional outcomes following closed reduction and casting.

Soft tissue interposition is a recognized phenomenon that can complicate closed reduction. In one study of 80 patients that required surgical intervention, it was demonstrated that 36 of the cases were not reducible due to interposition of the medial meniscus within the fracture site. Also implicated in the study was the anterior horn of the menisci and the transverse ligament.

This may account for the inability of a fragment to be reduced in extension and has been reported in the literature to account for $32 \%$ of non-reducible cases $[5,10]$. There is also a possibility for entrapment of the medial collateral ligament [11]. Currently no consensus has been reached with regard to the best surgical option. Broad options include open reduction and internal fixation or arthroscopic reduction and internal fixation [7].

Very little is documented about the incidence of symptomatic ACL laxity within the literature, however the incidence of asymptomatic ACL laxity is well known, albeit quite variable. [5, 12, 13, 14]. This highlights the importance of three dimensional imaging, especially in type II and type III fractures. Previous authors have advocated its use in delineating the degree of displacement and involvement of the tibial plateau and some suggest that MRI should be used over CT to reduce radiation risk [14, 15 , and 16]. In one study examining the use of 3D imaging and its effect on treatment planning and fracture classification, it was found that as the patient's investigations moved from radiographs to $\mathrm{CT}$ to MRI the fracture classification was changed in $6 \%$ and $21 \%$ of cases respectively. It was reported that MRI evaluation changed the treatment plan in $23 \%$ of cases [16].

This not only highlights the importance of the clinical examination of the patient and of the high grade of suspicion for such an easy to miss fracture, but also the importance of three dimensional imaging $[16,17]$

Stiffness (limitation of full flexion and/or extension) following surgical treatment could persist for up to 6 months, but would often improve with physiotherapy. If it did not then metalwork removal is beneficial. Follow- up of the patients in the current study have yielded good outcomes and Lysholm scores comparable to scores reported in the literature.

The prognosis for closed treatment of nondisplaced and reduced tibial spine fractures and for operative treatment of displaced fractures is good. Most series report healing with an excellent functional outcome despite some residual knee laxity. Potential complications include nonunion, malunion, arthrofibrosis, residual knee laxity, and growth disturbance [18, 19, 20, 21, 22, 23, and 24].

In summary, isolated paediatric tibial spine fractures can be successfully managed non-operatively in an extension cast and this should be the normal management of the type I injury. Displaced tibial spine fractures can also be initially managed in this way. Should a displaced fracture not reduce in extension cast then soft-tissue interposition should be suspected. Three dimensional imaging, such as a CT scan, should be used to assess the fracture displacement and anatomy to help guide management. An open knee arthrotomy or arthroscopy should be used to reduce and fix the fracture. This protocol has the potential to reduce the need for unnecessary imaging and surgery.

\section{References}

1. Skak SV, Jensen TT, Poulsen TD, et al. Epidemiology of knee injuries in children. Acta Orthop Scand. 1987;58(1):78-81

2. Chotel F, Raux S, Accadbled F, Gouron R, Pfirrmann C, Bérard J. Cartilaginous tibial eminence fractures in children: which recommendations for management of this new entity? Knee Surg Sports Traumatol Arthrosc 2016;24 (March (3)):688-96

3. Wilfinger C, Castellani C, Raith J, Pilhatsch A, Höllwarth ME, Weinberg AM. Nonoperative treatment of tibial spine fractures in children-38 patients with a minimum follow-up of 1 year. J Orthop Trauma 2009;23(August (7)):519-24 
4. Gans I, Baldwin KD, Ganley TJ. Treatment and management outcomes of tibial eminence fractures in pediatric patients: a systematic review. Am J Sports Med 2014;42(July (7)):1743-50

5. Edmonds EW, Fornari ED, Dashe J, Roocroft JH, King MM, Pennock AT. Results of displaced pediatric tibial spine fractures: a comparison between open, arthroscopic, and closed management. J Pediatr Orthop 2015;35(October- November (7)):651-6

6. Mulhall KJ, Dowdall J, Grannell M, McCabe JP. Tibial spine fractures: an analysis of outcome in surgically treated type III injuries. Injury 1999;30(4):289-92

7. Coyle C, Jagernauth S, Ramachandran M. Tibial eminence fractures in the paediatric population: a systematic review. J Child Orthop 2014;8(March (2)):149-59

8. Mann MA, Desy NM, Martineau PA. A new procedure for tibial spine avulsion fracture fixation. Knee Surg Sports Traumatol Arthrosc 2012;20:2395-2398

9. Gan Y, Xu D, Ding J, Xu Y. Tension band wire fixation for anterior cruciate ligament avulsion fracture: biomechanical comparison of four fixation techniques. Knee Surg Sports Traumatol Arthrosc 2012;20:909-915

10. Kocher MS, Micheli LJ, Gerbino P, Hresko MT. Tibial eminence fractures in children: prevalence of meniscal entrapment. Am J Sports Med 2003;31:404- 7.

11. 11. Hayes J, Masear V. Avulsion fracture of the tibial eminence associated with severe medial ligamentous injury in an adolescent: a case report and review of the literature. Am J Sports Med 1984;12:330-3.

12. Sapre V, Dwidmuthe SC, Bagaria V, Yadav S. Functional outcome in tibial spine fracture treated with arthroscopic pull through suture technique. J Orthop Traumatol Rehabil 2015;8:6-10.

13. Kocher MS, Foreman ES, Micheli LJ. Laxity and functional outcome after arthroscopic reduction and internal fixation of displaced tibial spine fractures in children. Arthroscopy 2003;19:1085-90.
14. Baxter MP, Wiley JJ. Fractures of the tibial spine in children: an evaluation of knee stability. J Bone Joint Surg Br 1988;70:228-30.

15. Griffith JF, Antonio GE, Tong CW, Ming CK. Cruciate ligament avulsion fractures. Arthroscopy 2004;20:80312.

16. Yacoubian SV, Nevins RT, Sallis JG, Potter HG, Lorich DG. Impact of MRI on treatment plan and fracture classification of tibial plateau fractures. J Orthop Trauma 2002;16:632-7.

17. Hargrove R, Parsons S, Payne R. Anterior tibial spine fracture: an easy fracture to miss. Accid Emerg Nurs 2004;12(3):173-5.

18. Bale RS, Banks AJ. Arthroscopically guided Kirschner wire fixation for fractures of the intercondylar eminence of the tibia. J R Coll Surg Edinb. 1995;40(4):260-262.

19. Berg EE. Pediatric tibial eminence fractures: arthroscopic cannulated screw fixation. Arthroscopy. 1995;11(3):328-331.

20. Louis ML, Guillaume JM, Launay F, et al. Surgical management of type II tibial intercondylar eminence fractures in children. J Pediatr Orthop B. 2008;17(5):231-235.

21. McLennan JG. The role of arthroscopic surgery in the treatment of fractures of the intercondylar eminence of the tibia. J Bone Joint Surg Br. 1982;64(4):477-480.

22. Mulhall KJ, Dowdall J, Grannell M, et al. Tibial spine fractures: an analysis of outcome in surgically treated type III injuries. Injury. 1999;30(4):289-292.

23. Reynders P, Reynders K, Broos P. Pediatric and adolescent tibial eminence fractures: arthroscopic cannulated screw fixation. J Trauma 2002;53(1):49- 54.

24. Hunter RE, Willis JA. Arthroscopic fixation of avulsion fractures of the tibial eminence: technique and outcome. Arthroscopy 2004;20(2):113-21.

\section{Correspondence to:}

Tepeneu Narcis Flavius,

"'Victor Babes"' University of Medicine and Pharmacy

P-ta Eftimie Murgu no. 2, Timisoara, Romania

Phone: 0040256220484

Fax: 0040256220484

E-mail: tepeneu.narcis@umft.ro 